\title{
Unpacking the Social Dimension of External Interruptions
}

\author{
Rikard Harr and Victor Kaptelinin \\ Department of Informatics \\ Umeå University, Sweden \\ \{rharr, vklinin\}@informatik.umu.se
}

\begin{abstract}
The paper systematically explores the social dimension of external interruptions of human activities. Interruptions and interruption handling are key issues in human-computer interaction (HCI) and computer-supported cooperative work (CSCW) research. However, existing research has almost exclusively dealt with effects of interruptions on individual tasks. In this paper we call for expanding the scope of analysis by including the effect of interruptions on the social context. We identify four facets of the social "ripple effect" of interruptions: location, communication, collaboration, and interpersonal relation. We discuss the advantages of extending the notion of interruptions and its implications for future research.
\end{abstract}

\section{Categories and Subject Descriptors}

H.5.3 [Information Presentation and Interfaces]: Group and Organization Interfaces - collaborative computing, computersupported cooperative work, synchronous interaction, theory and models.

\section{General Terms}

Design, Experimentation, Human Factors.

\section{Keywords}

Interruptions, interrupter, interruptee, social context, location, communication, collaboration, interpersonal relation.

\section{INTRODUCTION}

Modern communication technologies prompt task interruptions: for instance, e-mail clients may provide interruptions throughout the day when notifying about incoming messages [48]. As a consequence, knowledge work often takes place in work settings characterized by frequent interruptions [24, 36, 57, 61]. The problem is aggravated by the fact that the work of the knowledge worker consists, to a large degree, of tasks that involve high cognitive load and are therefore vulnerable for interruptions [6].

Interruptions are likely to continue to be a popular object of CSCW studies in the years to come. Despite a relatively strong history of research on the issue, dealing with interruptions

Permission to make digital or hard copies of all or part of this work for personal or classroom use is granted without fee provided that copies are not made or distributed for profit or commercial advantage and that copies bear this notice and the full citation on the first page. To copy otherwise, or republish, to post on servers or to redistribute to lists, requires prior specific permission and/or a fee.

GROUP'07, November 4-7, 2007, Sanibel Island, Florida, USA.

Copyright 2007 ACM 978-1-59593-845-9/07/0011_..\$5.00. remains a problem that still awaits effective and reliable solutions. In our view, a necessary condition for further progress is developing a deeper, more comprehensive understanding of interruptions that would take into account the actual complexity of the phenomena. Current studies of interruptions are mostly dealing with the effect of interruptions on individual work. There are examples of studies, in which the scope has been expanded, for instance, by including into analysis those individuals who are responsible for interruptions [51,69], but most studies only deal with individual tasks directly affected by an interruption, and often focus on a single technology or feature $[19,24]$.

In this paper we provide arguments that a narrow focus on individual tasks and individual users is an obstacle to further research. An adequate understanding and support of interruptions requires placing the phenomena into a broader context. Without taking into account a broader social context, interruptions cannot be even judged as negative or positive $[13,36,46,52,54,68,71]$. Furthermore, without taking into account the social dimension of interruptions we cannot understand the reasons why people react to interruptions in a certain way and how they use different interruption handling strategies under different circumstances.

The rest of the paper is organized as follows. The next section provides an overview and discussion of existing studies of interruptions in HCI and CSCW. The section concludes that an important next step in interruption research would be to widen the scope of analysis and include collective and organizational factors in order to complement the partial picture created by prior studies. The third section presents and illustrates four facets of the "ripple effect" of interruptions, that is, the effect that transcends the immediate impact of an interruption on the individual's task at hand. The facets of the "ripple effect" are described through the notions of location, communication, collaboration, and interpersonal relation. The fourth section reflects on the implication of the notions of the social dimension of interruptions - and the identified facets of the "ripple effect" -- for HCI and $\mathrm{CSCW}$ research. The fifth section discusses the limitations of existing technologies. Finally, the sixth section concludes the paper with a summary and reflections on the prospects for future research.

\section{STUDIES OF INTERRUPTIONS: AN OVERVIEW}

In this section we present an attempt to categorize previously conducted $\mathrm{HCI}$ and $\mathrm{CSCW}$ research on interruptions and interruption handling according to the foci of the studies, namely: (1) research concerning the effects of interruptions on the individual, (2) research concerning the ways to stop disruptive interruptions from occurring, and (3) research concerning the 
ways to limit the damage caused by interruptions. Some studies appear in several categories due to the fact that they touch upon several aspects of interruptions at the same time.

\subsection{The Effect of Interruptions on Individual Activities}

Most studies found interruptions to be intrusive and having almost exclusively negative effects [13, 46, 54, 68]. Interruptions are generally characterized as corporate time-wasters that we need to deal with. They have also been blamed for affecting our mental state negatively $[8,71]$. Some studies, however, describe a more complex picture and suggest that some effects of interruptions are not necessarily negative $[52,71]$.

For instance, positive effects of interruptions were found by Speier et al. [59, 60] and Bailey et al. [7, 8]. O'Conaill and Frohlich [52], who conducted a study of work practices of information workers using the shadowing observation technique, found the recipients of interruptions to experience some benefits from the interruptions in 64 percent of the cases.

Other researchers also reported a mixed effect of interruptions on task performance. The results of a series of experiments conducted by Burmistrov and Leonova [14] suggest that interruptions facilitate individual performance in case of simple tasks, but inhibit performance in case of complex tasks. McCrickard et al. [50] also observed both negative and positive effects of interruptions. Examples of positive effects included awareness of peripheral information, access to instantaneous communication, and fast availability of important information. This ambivalent characteristic of interruptions is the reason why the attitudes towards them are characterized by a tension between avoidance and appreciation [36].

Existing research provides ample evidence that interruptions are common in modern workplaces. In organizations workers spend a considerable amount of time having short conversations $[36,53$, 70], many of which -- up to 90 percent - are not planned [70]. This suggests that these conversations may imply interruptions for at least one of the involved parties [57]. O'Conaill and Frohlich [52] found that mobile professionals usually act in environments characterized by constant interruptions, where approximately 10 minutes in every hour are spent on being engaged in activities initiated by an interruption. Gonzalez and Mark [31] found that their subjects (analysts, managers and software developers) on average were able to focus on a task for about three minutes before switching to another task. Sproull et al. [62] found that 80 percent of the daily work of managers was spent in short interactions and that their activities were interrupted 21 percent of the time.

According to Cutrell et al. [20], one of the factors that determine the potential damage of an interruption is timing. Most damage is caused when interruptions occur during the evaluation phase of a task. Such interruptions result in longer completion times compared to interruptions that occur during other phases of work. Another aspect that affected the disruptive effect of an interruption was the relevance of an interruption to the current task. Interruptions, which were irrelevant to the current task, caused more disruption and longer resumption time than interruptions that were relevant to the task at hand. Similar results concerning the consequences of interruptions were found in other studies, as well $[2,7,12,22,59]$.

\subsection{Preventing Disruptive Interruptions from Occurring}

Since interruptions are often disruptive, a natural strategy of dealing with them would be to simply stop them from happening. The most obvious way to avoid being interrupted is to make people aware that we do not want to be disturbed. In the physical office this can be achieved quite easily, for example when we arrange the spatial layout of stacks of books and papers as an attempt to create a "wall" behind which we can work in peace and quiet [10] or when we keep our office doors closed [40]. Lightweight techniques of this kind are much more difficult to employ when it comes to computer-mediated interruptions. In computer-mediated communication availability is typically understood as a binary, "yes or no" state [44]. Some studies [42, 43] question this understanding. Instead, they suggest that people want to be constantly available -- but not for all sorts of communication. This statement leads to the concept of availability management, a concept defined as 'the ways in which a person signals to other persons in the surroundings (including also online contacts) if he/she is open to communication or not' [33].

According to Harr and Wiberg [33], there are two approaches for managing one's availability, the explicit approach and the implicit approach. By explicit availability management they refer to design of different kinds of technical support that consider availability as presence and enable users to toggle between diverse availability/presence profiles or modes, as in early versions of ICQ (users made explicit switches between diverse modes of status, 'away' or 'occupied'). There have also been some attempts to deal with availability through implicit means and two approaches can be identified, the strategy of automated calculation and the use of different kinds of office shares, i.e. technologies that connect several distributed offices together through some or several kinds of media.

Automated calculation is a strategy based upon automated information gathering from diverse input sensors, such as speech detectors (e.g., [27, 28, 29, 37]), or combinations of diverse sensors, such as sound and motion detectors (e.g., [9]). Employing this strategy has resulted in a number of examples of computer-based techniques that supervise the mouse and keyboard activity of the individual as an indicator of whether or not the individual is present in a certain setting. This information is then converted into a signal for others to act upon, such as icons with different colors and shapes [32, 67], or sounds [18, 32, 45].

The second strategy, the use of "office shares", employs various types of video glimpses [64], video snapshots [26, 38, 41], or Media spaces, $[1,11,15,30,34,47,56]$. These office shares enable individuals to verify the availability of others based upon the information presented through glimpses, snapshots, or audio/video transmissions.

Since the work of individuals, groups and organizations might benefit from some interruptions, while being disrupted by others, there have been attempts to develop different kinds of filtering systems [e.g. 9, 27, 28, 29] and explore more fine-grained availability management techniques [33]. As a whole, this line of research indicates that most people prefer taking the trouble of dealing with interruptions to shutting down completely from external interruptions and thus running the risk of missing valuable information. 


\subsection{Making Interruptions Less Harmful}

If individuals cannot shield themselves from interruptions, for instance, because they are concerned about missing valuable information, an alternative way to deal with interruptions could be trying to decrease the damage caused by interruptions that do occur. In section 2.1 we mentioned some studies investigating the disruptive effects of interruptions. These studies suggest certain strategies of making interruptions less harmful, such as managing the timing of an interruption or only allowing interruptions, which are relevant to the task at hand. For example, if sufficient awareness information is provided, the timing of interruptions could be adjusted to decrease the disruptive effect of an interruption $[2,22]$.

Other strategies for minimizing the damage caused by interruptions include using different communication channels or modal outputs. For example, interruptions can be made less disruptive by using different modalities such as heat, smell, sound, vibrations and light [5] to minimize interference between perceptual and cognitive processes involved in interruption handling and task performance.

An example of technology specifically designed to make interruptions less disruptive is The Negotiator system developed by Wiberg and Whittaker [69]. The system supports the user in handling interruptions that have already attracted attention of the individual; it aims to make interruption handling less cognitively demanding. Among other things The Negotiator allowed the receiver of an incoming call to negotiate with the sender an appropriate time for interaction if the received cannot take care of the interruption at the moment of the call. This way of dealing with interruptions does not stop them from occurring. In fact, it might increase the number of interruptions for the individual, but could make them less disruptive. The system makes it possible for the individual to decide upon the time when he or she wants to handle an interruption, and thus brings to synchronous communication some advantages of asynchronous media [52, 55]

Another way to cope with the disruptive effect of interruptions is to shorten the resumption lag, that is, the time needed to collect one's thoughts and resume working on a task when the interruption is over [3]. Altman and Trafton [3] examined the role of external cues associated with the interrupted task. It was found that providing cues that are available to the individual just before an interruption can help increase his or her performance immediately after the interruption. In a similar vein, Czerwinski et al. [23] found a navigable video log of the computer screen to be beneficial for resumption of a previous task after a longer period of time. However, reviewing those logs demands time from the user, which somewhat undermines the usefulness of the logs, since time is a scarce resource for many information workers [24].

\subsection{The Need for Expanding the Scope of Analysis}

The previous research, discussed above, indicates that when dealing with interruptions people face three fundamental dilemmas. If workers make themselves unavailable for interruptions they may be able to more fully focus on their current tasks, but by doing so they also increase the probability of missing important news. If workers provide ample information about the current status of their activities they may help others to select an optimal time for an interruption, but by doing so they also may jeopardize their privacy. If workers postpone dealing with an interruption to a more convenient time they could pay more attention to the task at hand, but by doing so they also engender one more thing to take care of in the future.

There are no simple universal solutions to these dilemmas. In each particular case individuals need to find optimal tradeoffs between seclusion and availability, openness and privacy, and direct or delayed handling of an interruption. Finding optimal interruption handling strategies is anything but trivial. Unfortunately, existing research does not provide much insight on how people select specific strategies depending on the specific context. Most prior studies of interruptions are laboratory experiments conducted in artificial controlled environments (e.g., [2, 3, 5, 8, 14, 19, 71]). Not all interruption research is based on controlled experiments; a number of papers report studies conducted in real work environments (e.g., [36, 57, 63]). However, studies of the latter type are relatively rare.

As a result, most studies - even those conducted in everyday settings - focus on individual behavior and attitudes towards interruptions $[2,3,5,14,24,25,35,57]$, while somewhat underplaying the importance of the social context, in which individuals, as members of teams, groups or organizations, suffer or benefit from interruptions.

The implications of explicitly or implicitly adopting the positivist paradigm in studies of groups and teams - and especially the way it promotes laboratory experiments as a "golden standard" of research - have been discussed elsewhere. For instance, Shea and Guzzo [58] argue that laboratory experiment is a less suitable method for studying team performance because it oversimplifies the natural contexts of teamwork. ${ }^{1}$

We believe an important next step in studying interruptions is to widen the scope of analysis and include the social context in interruption research. The social dimension of interruptions should become a key issue in interruption research because it can help: (a) understand the role interruptions play in work practices, (b) understand the strategies used by collaborating individuals to initiate and handle interruptions in concrete contexts, and (c) identify the prospects for technological support of people and organizations in managing interruptions as a part of their everyday work.

\section{BEYOND INTERRUPTIONS OF INDIVIDUAL TASKS}

As repeatedly emphasized throughout this paper, the focus of existing studies of interruptions has been predominantly on individual tasks. An interruption as an event is typically described in such studies by identifying the following aspects:

(a) An Actor carrying out Task A,

(b) An external Interruption: an external event that causes a disruption of the process of completing Task A,

(c) A reaction of the Actor to the Interruption,

(d) A resumption of Task A (optional, since interruptions may result in the abandonment of Task A).

\footnotetext{
1 Similar claims have been made by Arrow et al. [4] and Kaptelinin and Harr [39].
} 
However, this analytical framework, which does not include the social context, in which the event is taking place, is not sufficient. In the rest of this section we will identify a number of facets comprising the social dimension of interruptions. This is a preliminary exploration, and our aim is not to provide a definitive and comprehensive description of the social context. Our ambition is more modest: we propose a first draft of a conceptual map of the problem; a map that is expected to be further elaborated and revised in future research.

In the following sections we identify four different facets, or "dimensions", along which an interruption can have effects beyond particular tasks directly affected by the interruption.

The discussion below is only related to cases where another person causes an external disruption of a person's task. The cases of internal interruptions (or "self-interruptions"), such as cases when we suddenly remember that we have to do something and then switch to another task, as well as cases of "impersonal" interruptions, such as those caused by fire alarms or earthquakes, are outside the scope of our analysis. Furthermore, we do not consider the positive effects of interruptions, limiting our focus to negative effects. This leads us to the following definition of an external interruption: an external event that causes a disruption of the process of completing a task. ${ }^{2}$

\subsection{Interpersonal Relation}

When one person interrupts another, the interruption event takes place within the context of an interpersonal relation between the one who initiates the interruption (the interrupter) and the one who is interrupted (the interruptee). The event is, at least partly, determined by the past history of the relation, and, in turn, the event may influence the way that the relation is going to develop in the future (see Figure 1). For instance, the interruptee may feel obligated to return a favor received in the past and because of that may endanger his or her current task by positively responding to an interrupter's request.

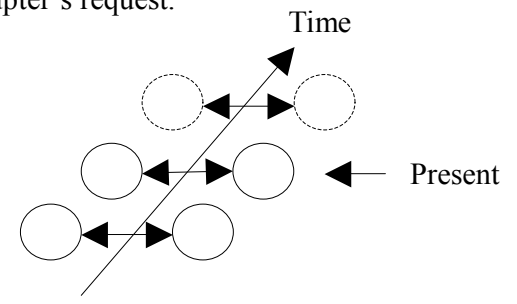

Figure 1. An interruption in the "historical" context of an
interpersonal relation

In general, the interrupter and the interruptee have different agendas and priorities, and their choice of strategies is likely to be determined by anticipated costs and benefits of available options. The interrupter has to assess the situation and make a decision about whether or not he or she can or should interrupt. If the interrupter decides not to interrupt, then a number of further decisions should be made, such as deciding to make an attempt later on and, probably, creating a reminder.

\footnotetext{
${ }^{2}$ Defining tasks is a separate issue, which is beyond the scope of this paper; one way to deal with it is to let the subjects define what their tasks are, cf. [24].
}

Other social factors such as power relations, work roles or friendship might also affect the behavior of both the interruptee and the interrupter. For instance, it is reasonable to believe that an interruptee is more inclined to accept an interruption from someone positioned higher up in the organizational hierarchy.

Therefore, most interruptions can be properly described as an unfolding interaction between two (or more) parties, in which they mutually ascertain each other's positions, establish priorities, assess available options, and negotiate a range of issues. For instance, the interaction between the interrupter and the interruptee can take the form of availability negotiation [69]. Other issues negotiated by the interrupter and interruptee can include the relative urgency of their respective tasks, local norms and rules, the impact of the outcome of the interruption on the interpersonal relation between the actors, and so forth.

\subsection{Location}

Even if an interruption is specifically directed at one person, it can also have an effect on other persons that happen to be at the same location. For instance, in certain settings, such as the theater, it is not uncommon to ask people in the audience to switch off their mobile phones. The main concern here is not about potential call receivers but rather about other people attending the performance, as well as the actors, who can be affected by the ring signals. Therefore, an interruption of one person may result in interruptions, often unintended, of other people, which we call "collateral disruptions" (see Figure 2).

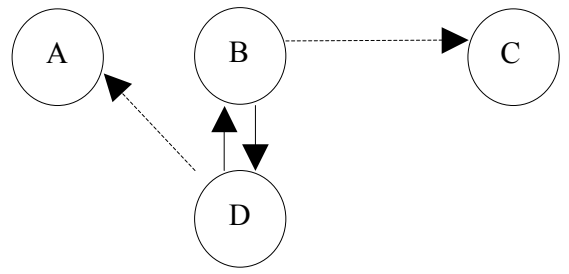

Figure 2. Collateral disruption

Figure 2 shows a collateral disruption, where the interaction between Actor D (the interrupter) and Actor B (the intended interruptee) also influences two other actors (Actor A and C). Actor $\mathrm{A}$ is disturbed by the actions of the interrupter (such as the ring signal), while Actor $\mathrm{C}$ is affected by the response of Actor $\mathrm{B}$ to the interruption (such as talking on the phone with Actor D).

A specific case of collateral disruptions is "traffic jam". This notion refers to various situations where people wait for their turn to be served or have to follow one after another through a limited "passageway" and where failing to keep moving will make other people stop. Examples of such situations include all kinds of lines, such as lines to the cashier in a grocery store or at an ATM (see Figure 3). "Traffic jam" is a version of collateral disruption where people can be affected not necessarily by actions of an intended interruptee but also by his or her inaction, the failure to keep going to avoid a bottleneck. 


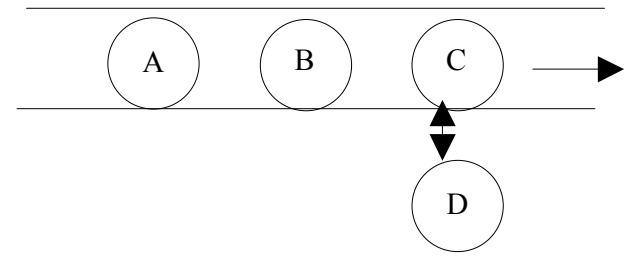

Figure 3. Traffic jam

\subsection{Communication}

Interrupted tasks carried out by individuals often include interaction with other people. Let us consider a general case of synchronous communication, where a person is involved in casual or serious conversation with other people. If the person is interrupted, the communication process often "freezes" - the others may need to wait until the interruptee is back. Figure 4 shows that sort of situation. Two actors (B and C) carry out a task through synchronous communication, either face-to-face communication or telecommunication. When Actor B deals with an interruption caused by Actor A (the interrupter), Actor $\mathrm{C}$ has to wait until Actor B is back.

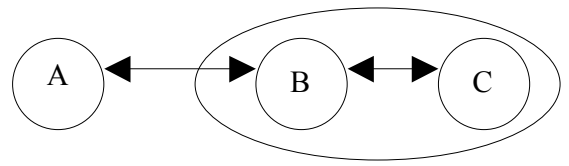

Figure 4. Freezing

\subsection{Collaboration}

The tasks carried out by interruptees can be - and typically are sub-tasks within collective activities, that is, activities collaboratively carried out by a group of people. When an individual's task is interrupted, the overarching collective activity is likely to be interrupted, as well. In some cases interruptions of collective activities are immediately obvious. For instance, when a card game player has to attend an urgent matter, other players may have to wait until he or she is back. This case is similar to "Freezing", shown in Figure 4.

In other cases the impact of individual task interruptions on collective activities can be less obvious and immediate, such as a deadline missed because a person had been "too busy with other things". Two examples of such cases are presented in Figure 5 and Figure 6. Figure 5 shows actors B and C, who collaboratively take care of a group task (GT), carried out within a collective activity (CA). If Actor A interrupts Actor B, then Actor C may need to cover for Actor B while Actor B is not involved in carrying out the task.

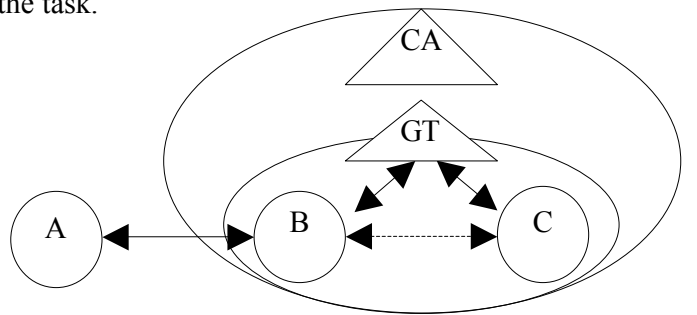

Figure 5. Cover for me
The type of interruptions of collective activities that we dub "Dropping the ball" is shown in Figure 6. Actors B and C take part in a collective activity through their contributions to the activity. They may not even communicate with each other directly, but Actor C may critically depend on the content, quality, and timeliness of the outcomes of the work done by Actor B. Therefore, when Actor B is interrupted by Actor A, it may cause a disruption of the collective activity and thus create an interruption for Actor C. Alternatively, an interruption of Actor B may cause a general disruption of the collective activity and Actor $\mathrm{C}$ can be affected even if he or she is not directly influenced by the outcomes of tasks carried out by Actor B.

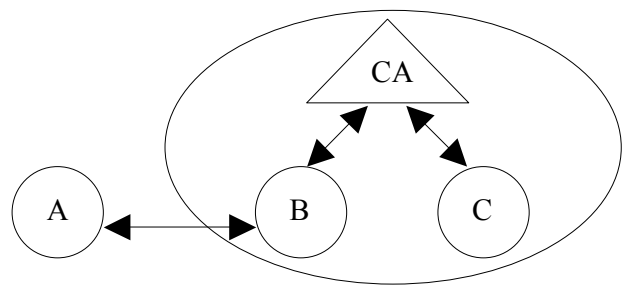

Figure 6. Dropping the ball

Finally, in some cases interruptions of individual tasks may have no tangible impact on a collective activity. Therefore, the relationship between interruptions of individual and collective activities is not straightforward. We believe a proper understanding of interruptions should combine analysis at the level of individual tasks with analysis at the level of collective activities.

The analysis above, however sketchy and straightforward, has a number of implications for the issues mentioned in the beginning of this paper, namely, understanding the effects of interruptions, the strategies used to manage interruptions, and the prospects for technological support. The analysis indicates that when dealing with these issues a focus on the individual task directly affected by an interruption is not sufficient: various ripple effects should be taken into consideration. We preliminary identify four types of ripple effects,":

- "Collateral disruptions" (an effect of the interruption in question on people in the same location),

- "Freezing" (the effect of the interruption on synchronous communication between the interruptee and other people),

- "Dropping the ball" (remote consequences of the interruption on other people who depend on the outcomes of interruptee's efforts within certain collaboration), and

- Various effects of the interruption on the interpersonal relation between the interrupter and the interruptee.

\section{IMPLICATIONS FOR RESEARCH}

The logical analysis of the social dimension of interruptions in the previous section produced a number of descriptive categories. They provide a basis for describing objective consequences of interruptions, that is, consequences that can materialize 
irrespective of whether or not people who handle interruptions are affected by them.

Therefore, the relevance of these categories to research of how people handle interruptions is not obvious. Are the identified categories only meaningful for an external observer or do they also affect the actual behavior of people who initiate or handle interruptions? In our view, this is a question that can be answered through empirical research.

In this section we argue that the aspects of the social dimension of interruptions discussed above do provide guidance in studies of interruptions. We will focus on two issues. First, we will discuss how the facets of the social dimension of interruptions can be used in generating hypotheses about the mechanisms of decision making in interruption handling. Second, we will discuss the implications of our analysis for developing research methodology suitable for studies of interruptions.

\subsection{Understanding Interruption Handling}

Earlier in this paper we identified several facets, or "dimensions", of the social context, along which interruptions of an individual's task may result in remote consequences transcending the effect on that particular task. Here we go a step further and make an assumption that people actually take into account the ripple effect of interruptions when making decisions about how to handle a particular interruption. Of course, we cannot claim that this assumption is correct (and, if yes, to what extent). What we claim is that the assumption can be assessed empirically. The typology of ripple affects proposed above provides a basis for formulating concrete hypotheses that can be tested in empirical studies. For instance, concrete studies can inquire how exactly interruption handling strategies depend on the relationship between the interrupter and interruptee; the presence of other people in the same location as the interruptee; the type of communication activities the interruptee is involved in at the moment of interruption; and the nature of collaborative activities in which the interruptee and/or the interrupter are taking part.

We believe that it is not sufficient to focus on isolated facets of the social dimension of interruptions. In real life-settings there is an interaction between interruption effects categorized in terms of location, communication, collaboration, and social relation; and they all interact with the interruption of the task at hand. In our view, studies of various interactions between "main" interruption effects can help reveal the whole picture of how/if task interruption and various ripple effects are comprehended by people and influence their strategies of handling interruptions. Research of that kind seems to be rather complicated and the taxonomy of ripple effects proposed in this paper appears to do little to reduce the complexity. However, the taxonomy does constrain the way that context can be treated. By identifying the four facets of the social dimension of interruptions it renders context complex but - hopefully - more manageable. There is a possibility that, if through extensive research, a coherent understanding of the context can eventually be achieved. A vague, unconstrained notion of context does not seem to have any chances at all.

\subsection{Searching for Appropriate Research Strategies}

Extending the focus of research from the direct effect of an interruption on the task at hand to the social context in which the interruption is taking place is associated with major challenges for research methodology. First of all, the possibilities to investigate social context by using the traditional methodology of controlled experiments are severely limited. An isolated task can be meaningfully modeled and studied in a controlled laboratory-type setting. However, an understanding of an interruption event in the context of an interpersonal relation between the interrupter and interruptee can only be achieved by taking into account the past and the potential future of the relation. The context of a relationship extends far beyond the time span of an interruption event, which makes it difficult, if possible at all, to model in a laboratory. Similar arguments apply to other facets of the social dimension of interruptions. Of course, one can create artificial conditions simulating various situations of collocation, communication, and collaboration. However, empirical data collected in such studies can be very different from what can be found in formally identical situations but taking place in real life contexts. For instance, when struggling to meet a real deadline (and facing real consequences for failing to do so) people may be much less inclined to get distracted from their tasks.

Another methodological challenge is the need to overcome the limitations of observational data. Observations can provide data on what people do during interruption handling. Observational data can also be a valuable source of evidence about the location, in which distracting events are taking place. But observations do not tell much about the social relation between the actors. Even though the observer can make an informed guess about the nature of a relationship, the guess may be wrong, since it does not take into account the past and the anticipated future, which are not directly observable. Communication can be fruitfully studied through observations if it is a face-to-face communication. Telecommunication is less amenable to an observational inquiry: just imagine observing a person who is talking on the phone and is intently listening during most of the conversation.

Therefore, research has to complement observational data with data obtained from the subjects. However, the usefulness of traditional interviews or diary studies is rather limited. Interviews that are heavily relying on subjects' memory may fail to reveal enough detail about interruption handling events, since the details may be quickly forgotten. Traditional diary studies [e.g. 24], in our view, do have a potential for exploring the social dimension of interruptions, but they are associated with massive interruptions caused by the need to make records in a diary. A version of diary studies, called elicitation studies [16], in which media captured by participants is used as a prompt for discussion in interviews, seem to be a promising alternative to more traditional methods. However, much still needs to be done to develop research methodology appropriate for studies of the social dimension of external interruptions.

\section{IMPLICATIONS AND CHALLENGES FOR DESIGN}

The main focus of this paper is on understanding interruptions in technology-rich environments, not design of technologies supporting interruption handling. However, the concepts introduced in the analysis above also have implications for design, even though these implications are rather indirect and tentative.

Undoubtedly, a number of existing technological solutions have been influenced, implicitly or explicitly, by concerns about the 
social context of interruptions. General-purpose communication tools, such as mobile phones and IM systems, provide the user with a variety of features for managing interruption handling depending on the context. The ease of switching to the "silent mode" or the "airplane mode" - intended to prevent collateral disruptions - has become a selling point for mobile phones. However, the usefulness of the feature critically depends on the ability of the user to remember to switch the phone to an appropriate mode.

More sophisticated technologies supporting interruption management are based on providing awareness clues for potential interrupters. Awareness support systems can, in principle, help avoid collateral disruptions and other types of "the ripple effect" of interruptions. However, so far this type of support has been rather limited. The main focus of design explorations has been on directly measurable parameters of individual activities. Such parameters are not reliable indicators of the social context. For instance, high keyboard/mouse activity may be an indicator of editing an important document, discussing an urgent issue over email or IM, or playing a computer game. As a result, existing systems, including experimental prototypes, rarely help assess the impact of an intended interruption on other people than their direct "targets". Further empirical studies systematically investigating the types of information about the social context that people actually take into account when initiating and handling interruptions can formulate more specific requirements to technologies supporting interruption handling. The concepts introduced in this paper, as well as future studies addressing the issues discussed above, may inform the search for more advanced technological solutions.

\section{CONCLUSIONS}

The starting point of our analysis is what we consider to be a shortcoming of previous research on interruptions. As our review of the previously conducted research indicates, the issue of interruptions has been almost exclusively addressed in experimental studies of individual activities. We claim that there is a need to extend the scope of analysis of interruptions to include not only individual tasks that are directly interrupted, but also less direct consequences of interruptions. The main conclusions of the discussion in the paper can be summarized as follows.

The "ripple effect" of interruptions. First, we identify four types of the "ripple effect" of interruptions that add to the effect on a directly interrupted individual task. While the impact of an interruption on the individual task at hand is undeniably of key importance, interruptions typically do not stop there. Interruptions of individual tasks may also cause "collateral disruptions" affecting people who happen to be in the same location as the interruptee. If the interruptee is engaged in communication, especially synchronous communication, an interruption can cause "freezing" of the unfolding process of communication. In addition, interruptions can cause the interruptee taking part in a collective activity to "drop the ball" and, thus, result in a disruption of collaboration. Finally, interruptions caused by other people always take place in the context of the social relation between the interrupter and the interruptee.

We do not claim that our analysis of the types of "ripple effects" of interruptions is either complete or sufficiently detailed. Undoubtedly, several other aspects of the social and organizational context affect interruptions and the strategies for dealing with them. Such aspects may include organizational culture, conventions, power relations, and so forth. The purpose of this paper is to present a preliminary exploration that can be further developed or revised in further research. However, even this preliminary analysis has at least two implications for studies of interruptions.

Are Ripple Effects Anticipated? The analysis above indicates that interruptions of individual tasks may cause ripple effects that can manifest themselves to an external observer. But do they influence the actual behavior of the interrupter and interruptee? Is their decision-making when initiating or handling an interruption affected by the anticipated ripple effects of an interruption? We believe this is an empirical question. Empirical studies of the actual strategies used by interrupters and interruptees appear to be the only way to find out how (and if) people are affected by anticipated ripple effects. What we claim here is that anticipated ripple effects may influence how people initiate or handle interruptions, and thus, taking them into account can help explain why certain people choose certain strategies.

Toward an Appropriate Research Methodology. When widening the focus from individual tasks to the social context of interruptions, we have to adapt new research methodologies. Arranging collective activities is not easily done in laboratory settings and transferring similar contextual factors from a work setting to an experimental setting is virtually impossible. This requires the researcher to conduct much more research in real life settings. As already mentioned, media elicitation and the feedback approach in diary studies appear especially promising, since they support the need for situated annotations of events that is vital for capturing the social dimension of interruptions and interruption handling.

When it comes to future work our next step is to empirically ground the importance of expanding the focus of analysis.

Toward Advanced Technological Support for Interruption Handling. Our analysis of existing technologies that have been developed to support collaboration and, in particular, interruption handling, indicates that designers have already been trying to take into account the ripple effect of interruptions. However, so far these attempts have not been based on a systematic analysis of the whole set of factors that influence the effect of interruptions. We think the preliminary "conceptual map" of the social context of interruptions proposed in this paper can be used as a simple but useful analytical tool that can help address interruptions taking place in real-life settings in a more systematic way.

\section{ACKNOWLEDGEMENTS}

The authors would like to thank four anonymous reviewers for valuable comments on an earlier draft of the paper.

\section{REFERENCES}

[1] Abel, M. 1990. Experiences in an exploratory distributed organization. In Intellectual Teamwork: Social Foundations of Cooperative Work, J. Galegher, R. E. Kraut, and C. Egido, Eds. Lawrence Erlbaum Associates, New Jersey, NJ, 489510.

[2] Adamczyk P. D. and Bailey B. P. 2004. If not now, when?: the effects of interruption at different moments within task execution. In Proceedings of the SIGCHI conference on 
Human factors in computing systems (Vienna, Austria, April 24 - 29, 2004). CHI'04. ACM Press, New York, NY, 271278.

[3] Altmann E. M. and Trafton J. G. 2004. Task interruption: Resumption lag and the role of cues. In Proceedings of the 26th annual conference of the Cognitive Science Society (Chicago, IL, August 5 - 7, 2004). CogSci 2004. Lawrence Earlbaum associates, Inc., Hillsdale, MI, 42-47.

[4] Arrow, H., McGrath, J. E., and Berdahl, J. L. 2000. Small groups as complex systems - formation, coordination, development, and adaption. Sage Publications.

[5] Arroyo E., Selker T. \& Stouffs A. 2002. Interruptions as multimodal outputs: Which are the less disruptive? In Proceedings of 4th IEEE International Conference on Multimodal Interfaces (Pittsburgh, PA, October 14 - 16, 2002). ICMI'02. IEEE Computer Society, Washington, DC, 479-483.

[6] Baecker, R. M., Grudin, J., Buxton, W. A. S., and Greenberg, S. 1995. Human-computer interaction: toward the year 2000. Morgan Kaufmann Publishers Inc.

[7] Bailey B. P., Konstan J. A. \& Carlis J. V. 2000. Measuring the effects of interruptions on task performance in the user interface. In Proceedings of IEEE International Conference on Systems, Man, and Cybernetics 2000 (Nashville, TN, October 8 - 11, 2000). IEEE Computer Society, Washington, DC, 2000, 757-762.

[8] Bailey B. P., Konstan J. A. \& Carlis J. V. 2001. The effects of interruptions on task performance, annoyance, and anxiety in the user interface. In Proceedings of Human-Computer Interaction (Tokyo, Japan, July 9 -13, 2001). INTERACT'01. IOS Press, Amsterdam, Netherlands, 593-601.

[9] Begole, J., Matsakis, N. E., and Tang, J. C. 2004. Lilsys: Sensing unavailability. In Proceedings of the 2004 ACM conference on Computer supported cooperative work (Chicago, IL, November 6 - 10, 2004). ACM Press, New York, NY, 511-514.

[10] Beyer, H., and Holtzblatt, K. 1998. Contextual design: Defining customer-centered systems. Morgan Kaufmann Publishers Inc.

[11] Bly, S. A., Harrison, S. R., Irwin, S. 1993. Media spaces: bringing people together in a video, audio, and computing environment. Commun. ACM. 36, 1 (Jan. 1993), 28-47.

[12] Burmistrov I. \& Leonova A. 1996. Effects of interruptions on the computerised clerical task performance. In Proceedings of the East-West International Conference on Human-Computer Interaction on Human Aspects of Business Computing (Moscow, Russia, August 12 - 16, 1996). EWHCI'96. ICSTI, Moscow, Russia, 21-29.

[13] Burmistrov I. and Leonova A.1997. Interruptions in the computer aided office work: Implications to user interface design. In Proceedings of the 13th Triennial Congress of the International Ergonomics Association (Tampere, Finland, June 29 - July 4, 1997). IEA'97. Finnish Institute of Occupational Health, Finland, 77-79.

[14] Burmistrov I. \& Leonova A. 2003. Do interrupted users work faster or slower? The micro-analysis of computerized text editing task. In Proceedings of HCI International 2003 (Crete, Greece, June 22 - 27, 2003). Lawrence Erlbaum Associates, Inc., New Jersey, NJ, 621-625.

[15] Buxton, B., and Moran, T.1990. EuroPARC's integrated interactive intermedia facility (IIIF): early experiences. In Proceedings of the IFIP WG 8.4 conference on Multi-user interfaces and applications (Heraklion, Crete, Sept. $24-26$, 1990). Elsevier North-Holland, Inc, Amsterdam, 11-34.

[16] Carter, S., and Mankoff, J. 2005. When participants do the capturing: The role of media in diary studies. In Proceedings of the SIGCHI Conference on Human Factors in Computing Systems (Portland, OR, USA, April 2 - 7, 2005). CHI'05. ACM Press, New York, NY, 899-908.

[17] Chen D. \& Vertegaal R. 2004. Using mental load for managing interruptions in a physiologically attentive user interface. In CHI'04 Extended Abstracts on Human Factors in Computing Systems (Vienna, Austria, April 24 - 29, 2004). CHI'04. ACM Press, New York, NY, 1513-1516.

[18] Cohen, J. 1993. "Kirk Here:” Using genre sounds to monitor background activity. In INTERACT '93 and CHI '93 Conference Companion on Human Factors in Computing Systems (Amsterdam, The Netherlands, April 24 - 29, 1993). CHI'93. ACM Press, New York, NY, 63-64.

[19] Cutrell E. B., Czerwinski M. \& Horvitz E. 2000. Effects of instant messaging interruptions on computing tasks. In CHI'00 Extended Abstracts on Human Factors in Computing Systems (The Hague, The Netherlands, April 1 - 6, 2000). CHI'00. ACM Press, New York, NY, 99-100.

[20] Cutrell E., Czerwinski M. \& Horvitz E. 2001. Notification, disruption, and memory: Effects of messaging interruptions on memory and performance. In Proceedings of HumanComputer Interaction (Tokyo, Japan, July 9 - 13, 2001). INTERACT'01. IOS Press, Amsterdam, Netherlands, 263269.

[21] Czerwinski M., Cutrell E. and Horvitz E. 2000. Instant messaging and interruption: Influence of task type on performance. In Proceedings of OZCHI 2000 (Sydney, Australia, December 4 - 8, 2000). OZCHI'00. Academic Press, Sydney, Australia, 356-361.

[22] Czerwinski M., Cutrell E. and Horvitz E. 2000. Instant messaging: Effects of relevance and time. In People and Computers XIV: Proceedings of HCI 2000, S. Turner and P. Turner, Eds. (Sunderland, UK, Sept. 5 - 8, 2000). SpringerVerlag, London, UK, 71-76.

[23] Czerwinski M. \& Horvitz E. 2002. An investigation of memory for daily computing events. In Proceedings of HCI 2002 (London, England, Sept. 2 - 6, 2002). Springer-Verlag, London, UK, 229-246.

[24] Czerwinski M., Horvitz E. \& Wilhite S.2004. A diary study of task switching and interruptions. In Proceedings of the SIGCHI conference on Human factors in computing systems (Vienna, Austria, April 24 - 29, 2004). CHI'04. ACM Press, New York, NY, 175-182.

[25] Dabbish L. \& Kraut R. 2004. Controlling interruptions: Awareness displays and social motivation for coordination. In Proceedings of the ACM Conference on Computer Supported Cooperative Work (Chicago, IL, USA, November 
6 - 10, 2004). CSCW'04. ACM Press, New York, NY, 182191

[26] Dourish, P., and Bly, S. 1992. Portholes: supporting awareness in a distributed work group. In Proceedings of the SIGCHI Conference on Human Factors in Computing Systems, P. Bauersfeld, J. Bennett, and G. Lynch, Eds. (Monterey, CA, May 3 - 7, 1992). CHI'92. ACM Press, New York, NY, 541-547.

[27] Fogarty J., Hudson S. E. \& Lai J. 2004. Examining the robustness of sensor-based statistical models of human interruptibility. In Proceedings of ACM Conference on Human Factors in Computing Systems (Vienna, Austria, April 24 - 29, 2004). CHI'04. ACM Press, New York, NY, 207-214.

[28] Fogarty J., Lai J., and Christensen J. 2004. Presence versus availability: The design and evaluation of a context-aware communication client. Int. J. Hum-Comput. St. 61, 3 (Sept. 2004), 299-317.

[29] Fogarty J., Hudson S. E., Atkeson C. G., Avrahami D., Forlizzi J., Kiesler S., Lee J. C. \& Yang J. 2005. Predicting human interruptibility with sensors. ACM Trans. CompHum. Interact. 12, 1 (Mar. 2005), 119-146.

[30] Gaver, W. W., Moran, T., Maclean, A., Lövstrand, L., Dourish, P., Carter, K., Buxton, W. 1992. Realizing a video environment: EuroPARC's RAVE system. In Proceedings of the SIGCHI conference on Human factors in computing systems (Monterey, CA, May 3 - 7, 1992). CHI'92. ACM Press, New York, NY, 27-35.

[31] Gonzalez V. M. and Mark G. 2004. "Constant, constant, multi-tasking craziness": Managing multiple working spheres. In Proceedings of the SIGCHI conference on Human factors in computing systems (Vienna, Austria, April 24 - 29, 2004). CHI'04. ACM Press, New York, NY, 113120.

[32] Greenberg, S. 1996. Peepholes: Low cost awareness of one's community. In Conference companion on Human factors in computing systems: common ground (Vancouver, BC, April 13 - 18, 1996). CHI'96. ACM Press, New York, NY, 206207.

[33] Harr, R., and Wiberg, M, "Lost in translation: investigating the ambiguity of availability cues in an online media space", Behaviour \& Information Technology, 2007, in press.

[34] Heath, C. and Luff, P. 1991. Disembodied conduct: Communication through video in a multimedia environment. In Proceedings of the SIGCHI conference on Human factors in computing systems: Reaching through technology (New Orleans, Louisiana, April 27 - May 2, 1991). CHI'91. ACM Press, New York, NY, 99-103.

[35] Horwitz, E., and Apaible, J. 2003. Learning and reasoning about interruption. In Proceedings of the 5th international conference on Multimodal interfaces (Vancouver, BC, November 5 - 7, 2003). ICMI '03. ACM Press, New York, NY, 20-27.

[36] Hudson, J., Christensen, J., Kellogg, W.A., Erickson, T. 2002. "I'd Be Overwhelmed, But It's Just One More Thing to Do:" Availability and Interruption in Research Management. In Proceedings of the SIGCHI Conference on
Human Factors in Computing Systems: Changing Our World, Changing Ourselves (Minneapolis, MN, April 20 25, 2002). CHI'02. ACM Press, New York, NY, 97-104.

[37] Hudson, S., Fogarty, J., Atkeson, C., Avrahami, D., Forlizzi, J., Kiesler, S., Lee, J., and Yang, J. 2003. Modeling user behaviour: Predicting human interruptibility with sensors: A Wizard of Oz feasibility study. In Proceedings of the SIGCHI conference on Human factors in computing systems (Ft. Lauderdale, FL, April 05 - 10, 2003). CHI'03. ACM Press, New York, NY, 257-264.

[38] Johnson, B., and Greenberg, S. 1999. Judging People's availability for interaction from video snapshots. In Proceedings of the Thirty-Second Annual Hawaii International Conference on System Sciences- Vol. 1 - Vol. 1 (Hawaii, HI, January 05 - 08, 1999). HICSS '99. IEEE Computer Society, Washington, DC, 1026.

[39] Kaptelinin, V., and Harr, R. 2007. The ripple effects of interruptions: Unpacking the social dimension of external disruption. Working Paper WP-07.01. Department of Informatics, University of Umeå.

[40] Kristoffersen, S., and Ljungberg, F. 1999. An empirical study of how people establish interaction: implications for CSCW session management models. In Proceedings of the CHI 1999 Conference on Human factors in computing systems (Pittsburgh, PA, May 15 - 20, 1999). CHI'99. ACM Press, New York, NY, 1-8.

[41] Lee, A., Schlueter, K., Girgensohn, A. 1997. NYNEX Portholes: Initial user reactions and redesign implications. In Proceedings of the international ACM SIGGROUP conference on supporting group work: the integration challenge (Phoenix, AZ, Nov. 16 - 19, 1997). Group'97. ACM Press, New York, NY, 385-394.

[42] Ljungberg, F. 1996. An initial exploration of communication overflow. In proceedings of the 2nd International Conference on the Design of Cooperative Systems (Sophia Antipolis, France, June 12 - 14, 1996). COOP'96. INRIA Press, Rocquencourt, 19-36.

[43] Ljungberg, F. and Sörensen, C. 1996. Communication deficiency and switching mechanisms. In proceedings of 4th European Conference on Information Systems, Vol. 2, J. D. Coelho et al, Eds. (Lisbon, Portugal, July 2 - 4, 1996). (ECIS'96). Ficha Técnica, Portugal, 1113-1119.

[44] Ljungberg, F. 1999. Exploring CSCW mechanisms to realize constant accessibility without inappropriate interaction. Scand. J. Info. Syst. 11, 2 (July 1999), 115-136.

[45] Lövestrand, L. 1991. Being Selectively Aware with the Khronika System. In Proceedings of the European Conference on Computer Supported Cooperative Work (Amsterdam, The Netherlands, Sept. 24 - 27, 1991). ECSCW'91. Kluwer Academic Publishers, Dordrecht, 265278.

[46] Mandler, G. 1984. Mind and Body. WW Norton \& Company.

[47] Mantei, M., Baecker, R., Sellen, A., Buxton, W., Milligan, T., Wellman, B. 1991. Experiences in the use of a media space. In Proceedings of the SIGCHI conference on Human factors in computing systems (New Orleans, LA, April 27 - 
May 2, 1991). CHI'91. ACM Press, New York, NY, 203208.

[48] Markels, A. 1997. "Memo 4/8/97, FYI: Messages inundate offices”. Wall Street Journal (April 8, 1997), B1-8.

[49] Milewski, A.E., and Smith, T.M. 2000. Providing presence cues to telephone users. In Proceedings of the 2000 ACM conference on Computer supported cooperative work (Philadelphia, PA, December 2 - 6, 2000). CSCW'00. ACM Press, New York, NY, 89-96.

[50] McCrickard, D. S., Chewar, C. M., Somervell, J. P., and Ndiwalana, A. 2003. A model for notification systems evaluation assessing user goals for multitasking activity. ACM T. Comput-Hum. Interact. 10, 4. (Dec. 2003), 312338.

[51] Nardi, B. A., Whittaker, S., Bradner, E. 2000. Interaction and outeraction: instant messaging in action. In Proceedings of the 2000 ACM conference on Computer supported cooperative work (Philadelphia, PA, December 2 - 6, 2000). CSCW'00. ACM Press, New York, NY, 79-88.

[52] O'Connail, B., and Frohlich, D. 1995. Timespace in the workplace: Dealing with interruptions. In Conference companion on Human factors in computing systems (Denver, CO, May 07 - 11, 1995). CHI' Companion 95. ACM Press, New York, NY, 262-263.

[53] Panko, R. R. 1992. Managerial communication patterns. J. Org. Comput. 2, 1 (1992), 95-122.

[54] Perlow, L. A. 1999. The time famine: toward a sociology of work time. Admin. Sci. Quart. 44, 1 (Mar. 1999), 57-81.

[55] Rodenstein, R., Abowd, G. and Catrambone, R. 1999. OwnTime: A system for timespace management. In Conference on Human Factors in Computing Systems (Pittsburgh, PA, May 15 - 20, 1999). CHI '99. ACM Press, New York, NY, 200-201.

[56] Root, R. W. 1988. Design of a multi-media vehicle for social browsing. In Proceedings of the 1988 ACM conference on Computer-supported cooperative work (Portland, OR, Sept. 26 - 28, 1988). CSCW'88. ACM Press, New York, NY, 2538.

[57] Rouncefield, M., Viller, S., Hughes, J., and Rodden, T. 1994. Working with constant interruptions: CSCW and the small office. In Proceedings of the 1994 ACM conference on Computer supported cooperative work (Chapel Hill, NC, Oct. 22-26, 1994). CSCW'94. ACM Press, New York, NY, 275-286.

[58] Shea, G.P. and Guzzo, R.A. 1987. Groups as Human Resources. In Research in Human Resources and Personal Management, K.M. Rowland and G.P. Ferris, Eds. JAI Press, Greenwich, CT, 323-356.

[59] Speier C., Valacich J. S. \& Vessey I. 1997. The effects of task interruption and information presentation on individual decision making. In Proceedings of the eighteenth international conference on Information systems (Atlanta, GA, Dec. 14 - 17, 1997). ICIS'97. Association for Information Systems, Atlanta, GA, 21-36.

[60] Speier C., Valacich J. S. \& Vessey I. 1999. The influence of task interruption on individual decision making: An information overload perspective, Decision Sci. 30, 2 (Spring 1999), 337-360.

[61] Speier C., Vessey I. \& Valacich J. S. 2003. The effects of interruptions, task complexity, and information presentation on computer-supported decision-making performance. Decision Sci. 34, 4 (Fall 2003), 771-797.

[62] Sproull, L. S. 1984. The Nature of managerial attention. In Advances in Information Processing in Organizations, L.S. Sproull \& P.D. Larkey, Eds. Jai Press Inc., Greenwich, CT, 9-27.

[63] Szóstek A. M., and Markopoulos P. 2006. Factors defining face-to-face interruptions in the office environment. In CHI '06 extended abstracts on Human factors in computing systems (Montréal, Québec, April 22 - 27, 2006). CHI’06. ACM Press, New York, NY, 1379-1384.

[64] Tang, J. C., Isaacs, E., Rua, M. 1994. Supporting distributed groups with a montage of lightweight interactions. In Proceedings of the 1994 ACM conference on Computer supported cooperative work. (Chapel Hill, NC, Oct. 22 - 26, 1994). CSCW'94. ACM Press, New York, NY, 23-34.

[65] Tang, J. C., Yankelovich, N., Begole, J., Van Kleek, M., Li, F., Bhalodia, J. 2001. ConNexus to awarenex: extending awareness to mobile users. In Proceedings of the SIGCHI conference on Human factors in computing systems (Seattle, Washington, March, 2001). CHI'01. ACM Press, New York, NY, 221-228.

[66] Want, R., Hopper, A., Falcão, V., and Gibbons, J. 1992. The Active Badge Location System. ACM T. Inform. Syst. 10, 1 (Jan. 1992), 91-102.

[67] Wax, T. 1996. Red light, green light: Using peripheral awareness of availability to improve the timing of spontaneous communication. In Proceedings of CSCW'96 Conference on Computer Supported Cooperative Work (Short papers) (Boston, MA, Nov. 19 - 20, 1996). CSCW'96. ACM Press, New York, NY, 443-444.

[68] Weick, K. 1995. Sensemaking in organizations. Sage Publications Inc.

[69] Wiberg, M., \& Whittaker, S. 2005. Managing Availability: Supporting Lightweight Negotiations to Handle Interruptions. ACM T. Comput-Hum. Interact. 12, 4 (Dec. 2005), 356-387.

[70] Whittaker, S., Frohlich, D., and Daly-Jones, O. 1994. Informal workplace communication: What is it like and how might we support it? In Proceedings of the SIGCHI conference on Human factors in computing systems, (Boston, MA, April 24 - 28, 1994). CHI'94. ACM Press, New York, NY, 131-137.

[71] Zijlstra F. R. H., Roe R. A., Leonova A. B. \& Krediet I. 1999. Temporal factors in mental work: Effects of interrupted activities. J. Occup. Org. Psy. 72, 2 (June. 1999), 163-185. 